\title{
Urgent Health Care Re- Birth
}

\author{
Julie Rammal* \\ George Washington University, USA \\ *Corresponding Author: Julie Rammal, George Washington University, USA.
}

Received: April 18, 2019; Published: June 07, 2019

DOI: $10.31080 /$ ASPS.2019.03.0299

The health care is entering an interesting era that will be divided in two separate extremities: medicine and technology and holistic spiritual health care. The future of medicine depends on the evolvement of each individual, their education, experience, income, and adaptation to the new world. As Darwin said, "It is not the strongest of the species that survive, nor the most intelligent, but the one most responsive to change".

As we look back at history, the father of medicine, Hippocrates, actually looked at medicine as a whole, or what we call today holistically. Plato had stated, "The certain knowledge of nature is solely possible from medicine and only when it is correctly approached as a whole". At that time, a Hippocratic Oath was crated as a promise to sustain the art of medicine and to act in patients' interests. However; from $460 \mathrm{BC}$ we have seen a massive evolvement of what medicine really is all about.

Even in ancient Egypt, the ancient Egyptians required all doctors to be literate and clean in body and spirit.

However, today we see a massive evolvement of medicine, phar$\mathrm{ma}$, and the healthcare industry that is far from what is was meant to be. Medicine is marketed, sold, with enormous profits, and even with all the medicine we seem to be getting sicker and face new rising illnesses, and epidemics that are constantly spreading.

Surely, today's health care has grown to be more like a sick care. It is not designed to keep us healthy, but to only cure sickness and more sicknesses. As many of us have begun to realize this, we are entering a new spiritual era or re-awakening. We are returning back to holistic medicine to keep ourselves, healthy and balanced rather than to just wait for a sickness to come and cure it. However; it may not be enough, as the earth has become so infected can we really come back to basics? Or will we begin to evolve and re-start health and life in our new cocoon compounds? Will humans now re-create human made compounds where we build organic plants, have air filtering systems, artificial sunlight and these compounds will be sold to the wealthy? We will no longer have "nature," we will have to temporarily re-create artificial living environments until we are able to find a way to live in Mars if we are saved with time.

Therefore, the future of medicine depends on us, and the steps we urgently take today to understand our body, mind and spirit and how we fit in a connected universe. We can choose the modern or holistic approach, however, at the end nature will always win. No matter what we create in modern medicine, we will be forced to return back to the basics and re-evolve from there to survive as our bodies are not ready for these rapid medical advancements.

Although holistic medicine was the birth of medicine, and later evolved to modern medicine, it is again beginning to evolve back to holistic approaches to health. Modern and holistic medicine will eventually collide together, and we will see a spiritual rebirth of medicine in a few centuries if not sooner. This will occur after we are done exploring all we could have with medicine and understand that connection to ourselves is our primary source of healing. The power of our mind, and understanding our inner anatomy, past life, karma, body language and symptoms, and the life we currently carry, we have the inner power to self heal. We can reengineer ourselves to be better aligned and live a happier health life, when our mind and heart are open. We must begin to follow the universal laws of nature: to love and be loved, and then healing begins.

Our bodies are not designed for the evolution of medicine at the pace we are predicted to be in soon. No matter how much we excel in modern medicine we must understand how far we have gone away from what true medicine is. We are entering an unknown zone.

In a few decades, we will have massive new health epidemics, pertaining heart, and brain (thoughts, mind etc), which I label as the, "Automimmune disease of the human being". We are constantly attacking ourselves and not understanding ourselves. Note, the brain and heart are the first things that develop in a fetus to give it life. If these two things are attacked, with the destruction of air 
quality (in which lungs connect us to a higher spiritual consciousness) we are looking more at the destruction and extinction of the human specie as a whole.

The human specie is a spiritual specie, a soul, and it follows the natural laws of life. If we do not abide to our means of existence we create illnesses, diseases, and catastrophe where no medicine will be able to save the human specie. An era of diseases, epidemics will continue to spread, and the future of medicine will exist in those who understand their body, mind, and soul and act and live within nature's laws of existence.

Today, with the arrival of molecular and industrialized technology, modern medicine no longer follows the Hippocratic Oath or ancient Egyptians philosophy which was the base birth of medicine. We are going further and further away from the birthplace of what medicine is. We are coming to a point where the human specie will have to be prepared for nature's response.

The future in modern medicine will continue to advance and become: digitalized, manufactured, and re-engineered etc. People will have their tissues re-engineered, cells may cure illnesses (focused on not killing the disease but growing parts from within us to heal). New-borns will be scanned and given health chips at birth to see who is more susceptible to a certain illness. Health care will be more digitally connected, where we will not have a live doctor patient experience anymore. We may have sensors in our bodies to detect when we might be getting sick. Pills will become old fashioned, and will be something that you can easily make and buy as if you are buying a soda from a machine. There will be many more health devices and apps. People will get lost with the amount of medicine advancements, and will divide more and more into being their own doctors for themselves as they enter a spiritual awakening. After the advancement of medicine, we will return to the universe, planets, astrology and stars to understand that medicine is not about what we put in ourselves it is about how to stay balanced, in connection with one-self when all else is out of balance. The healthcare will change again, and return back to empowering clients, training the brain to heal and using their own mental, body, and spirit to find their health.

Therefore, to be ahead of the change one must start by exploring their own body, mind and spirit.

Volume 3 Issue 7 July 2019

(C) All rights are reserved by Julie Rammal. 